\title{
Análise do Projeto de Proteção a Jovens em Território Vulnerável: vínculos e reconhecimento
}

\author{
Tatiana Sampaio de Souza \\ Mestre em Sociologia pela Universidade Federal do Rio Grande do Sul. \\ Professora no Instituto de Ensino Superior Cenecista de Unaí, \\ Unaí, Minas Gerais, Brasil \\ sampaiodesouza.adv@hotmail.com
}

\begin{abstract}
Resumo $\mathrm{O}$ artigo analisa a projeção de vínculos e esferas de reconhecimento na vida dos participantes do Projeto de Proteção a Jovens em Território Vulnerável (Protejo) no Brasil. A referida análise realiza-se a partir das teorias desenvolvidas por David Zimerman e Axel Honneth. Como procedimento metodológico foi empregada a realização de entrevistas semiestruturadas. Em conclusão, verificou-se que a formação de vínculos e esferas de reconhecimento na vida dos jovens ao longo de sua socialização influencia diretamente seus cotidianos e seus relacionamentos dentro e fora do projeto. Apesar de apresentar algumas falhas, no sentido de não preparar os jovens para o término e descontinuidade do projeto, o Protejo mostra-se como positivo na vida deles, por fortalecer a formação dos vínculos e esferas de reconhecimento investigados.
\end{abstract}

Palavras-chave: juventude, sociedade, políticas públicas, reconhecimento, vínculos.

\section{Introdução}

A fase da adolescência e juventude é marcada por intensas transfor-

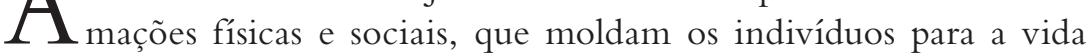
adulta. Essas transformações realizam-se a partir da socialização dos indivíduos, tanto primária quanto secundária. No entanto, em qualquer momento de seu desenvolvimento os sujeitos articulam vínculos uns com os outros e projetam em suas ações desdobramentos de esferas de reconhecimento que se estabelecem ao longo da vida. A juventude, no entanto, possui a singularidade de ser uma fase de acentuado processo de desenvolvimento, e, assim sendo, os desdobramentos dessas relações ocorrem com muito mais intensidade do que em qualquer outra fase da vida do ser humano.

No caso de jovens que se encontram em situação de risco social, elementos externos contribuem em grande escala para acentuar todas essas transformações. Em grande medida, os programas de políticas públicas têm se preocupado com esses fatores externos e objetivos, tais como dificuldades econômicas e financeiras, tráfico e uso de drogas, prevenção à criminalidade e à violência. Mas além desses fatores, existem outros de cunho subjetivo, que dizem respeito ao relacionamento que os jovens estabelecem em projetos com seus colegas e profissionais da equipe técnica. Por essa razão, torna-se interessante investigar os reflexos de vínculos e de reconhecimento na socialização dos jovens atendidos e os desdobramentos desses em seus cotidianos e em suas re- 
lações sociais, pois tais aspectos contribuem para uma melhor aceitação dos projetos pelos jovens e o consequente êxito das políticas públicas implementadas.

O objetivo principal deste artigo é a realização de uma abordagem sobre a projeção de vínculos e esferas de reconhecimento na vida dos jovens participantes do Projeto de Proteção a Jovens em Território Vulnerável (Protejo). Os resultados apresentados advêm de estudo qualitativo realizado para a elaboração de minha dissertação de mestrado, cuja pesquisa empírica ocorreu no período de abril de 2011 a março de 2012, no Protejo, implantado no território de paz do bairro Santo Afonso, localizado na cidade de Novo Hamburgo, Rio Grande do Sul.

O público-alvo do Protejo são jovens em situação de risco social, na faixa etária de 15 a 24 anos, e seu objetivo principal é a promoção da proteção dos jovens mediante ações pedagógicas. Esse projeto está inserido no Programa Nacional de Segurança Pública com Cidadania (Pronasci), que cuida da articulação entre políticas sociais e políticas de segurança. Segundo o Ministério da Justiça, o Pronasci prioriza a prevenção, incluindo ações de ordenamento social e segurança pública, tendo como público-alvo a mesma população atendida pelo Protejo, além de profissionais da segurança pública, presos ou egressos do sistema prisional, e reservistas (Brasil, 2008).

Para a pesquisa foram entrevistados dez adolescentes, além de dois técnicos e a coordenadora pedagógica do Protejo. No entanto, como alguns dos adolescentes entrevistados eram menores de idade, não foi possível utilizar todas as entrevistas, uma vez que os pais de quatro deles não puderam ou não quiseram assinar os termos de consentimento. Dos entrevistados cuja análise das respostas foi realizada, dois são do sexo masculino e quatro, do sexo feminino, com idades de 15 a 24 anos. A fim de se manter o anonimato dos jovens, seus nomes verdadeiros foram preservados. Para as entrevistas foi empregado um roteiro de questões semiestruturadas; no entanto, a forma de abordagem variou de acordo com as peculiaridades de cada caso e de cada entrevistado.

O texto deste artigo está dividido em cinco subitens: o primeiro contém a introdução, com a apresentação da pesquisa e da metodologia utilizada; o segundo apresenta o referencial teórico; o terceiro traz a análise da projeção de vínculos e esferas de reconhecimento dentro do Protejo; e o quarto traz as considerações finais.

Importante salientar que não se pretende esgotar o tema, e que os resultados ora apresentados são parciais, sendo que a finalidade principal deste artigo consiste na ampliação do espaço de problematização e discussão sobre as ações de políticas públicas voltadas a jovens em situação de risco social, como é o caso do Protejo.

\section{Teoria do reconhecimento de Honneth e os quatro vínculos de Zimerman}

A investigação da trajetória de vida dos jovens atendidos por programas de políticas públicas como o Protejo nos diz muito quando estamos interessados nas causas e motivos de evasão. Além daquelas causas "visíveis" e já conhecidas por todos - tais como as dificuldades socioeconômicas, a vulnerabilidade social, a violência intra e extrafamiliar, e principalmente a glamourização do tráfico de drogas, constantemente presentes na vida de grande parte dos adolescentes, responsáveis, na maior parte das vezes, pelo próprio ingresso deles na criminalidade - existem outros fatores que nem sempre recebem a devida atenção dos programas destinados aos jovens em situação de vulnerabilidade e risco social, que estão ligados a aspectos psicossociais relacionados à revolta, à depressão, à baixa autoestima e à própria carência de amor por parte de muitos.

Axel Honneth (2003) afirma que existem padrões de reconhecimento subjetivos que influenciam diretamente na vida das pessoas. As três esferas de reconhecimento com as quais o autor trabalha são o Amor, o Direito e a Solidariedade. No Amor, os princípios de reconhecimento seriam as necessidades e os sentimentos; no Direito, a igualdade legal; e na Solidariedade, as contribuições formais. Já a autorrelação prática desses padrões de reconhecimento seria, no caso do Amor, a autoconfiança; no Direito, o autorrespeito; e na Solidariedade, a autoestima. Quando qualquer desses padrões de reconhecimento encontra-se violado, acarretando formas de desrespeito, surgem consequências, tais como os maus-tratos e a violação, para o Amor; a privação de direitos e a exclusão, para o Direito; e as degradações e ofensas, para a Solidariedade (Honneth, 2003). Na pesquisa em foco, investigou-se a projeção dessas formas de reconhecimento na vida dos jovens atendidos pelo Protejo na cidade de Novo Hamburgo (RS), e a presença ou não de desrespeito a esses padrões, considerando os períodos anteriores a seu ingresso no projeto e durante sua permanência.

No desenvolvimento da esfera do Amor, Honneth (2003) recorre ao trabalho de Winnicott, "um pediatra com postura psicanalítica que procura obter, no quadro do tratamento de distúrbios comportamentais psíquicos, esclarecimentos acerca das condições 'suficientemente boas' da socialização de crianças pequenas” (p. 164).

A grande questão que ocupou os estudos de Winnicott durante quase toda sua vida foi esclarecer como se constituía o processo de interação, mediante o qual mãe e filho podem se separar do estado de di- 
ferenciação "ser-um” aprendendo a se aceitar e amar como pessoas independentes (apud Honneth, 2003, p. 165). E, na busca pela resposta a essa questão, Winnicott explora todo um universo de desenvolvimento da criança até a fase adulta, explorando as relações de amizade e amor desenvolvidas pelo ser humano durante sua existência.

Honneth (2003), por sua vez, apoiado na filosofia hegeliana do direito e levando em conta os estudos de socialização de Winnicott, bem como as contribuições de Jessica Benjamin acerca das deformações patológicas da relação amorosa, elabora um conceito de amor específico da teoria do reconhecimento. O autor explica que o Amor precede toda a forma de reconhecimento recíproco, e afirma:

Visto que esta relação de reconhecimento prepara o caminho para uma espécie de auto relação em que os sujeitos alcançam mutuamente uma confiança elementar em si mesmos, ela precede, tanto lógica como geneticamente, toda outra forma de reconhecimento recíproco: aquela camada fundamental de uma segurança emotiva não apenas na experiência, mas também na manifestação das próprias carências e sentimentos, propiciada pela experiência intersubjetiva do amor, constitui o pressuposto psíquico do desenvolvimento de todas as outras atitudes de auto respeito. (Honneth, 2003, p. 177)

Portanto, a esfera de reconhecimento do Amor está diretamente relacionada com o desenvolvimento da autoconfiança dos sujeitos, e por isso é tão importante que os programas sociais destinados aos jovens em situação de risco social ou em conflito não apenas com a lei, mas muitas vezes com o próprio rumo de suas vidas, deem atenção a ela.

Assim também são igualmente importantes as demais esferas de reconhecimento da teoria de Honneth, pois o autorrespeito, no caso do Direito, e a autoestima, no caso da Solidariedade, são fundamentais para o desenvolvimento do jovem e influenciam diretamente os sentimentos de acolhimento e pertencimento ao grupo dentro dos programas de apoio.

Enquanto Honneth trabalha com as formas de reconhecimento, Zimerman (2010), psicanalista brasileiro com particular interesse por distintas áreas de conhecimento, dentre elas as ciências sociais, trabalha com a formação dos quatro vínculos na personalidade dos indivíduos. Segundo o autor, "a noção de 'vínculo' é de fundamental importância no desenvolvimento da personalidade da criança, sendo que essa afirmativa está baseada na inquestionável sentença de que 'o ser humano constitui-se sempre a partir de um outro"” (Zimerman, 2010, p. 21).

Considerando vários enfoques teóricos, o autor fundamenta seu trabalho na teoria de Wilfred Bion, psicanalista britânico que enfatiza uma tensão entre emoção e não emoção, com a formação dos vínculos do amor, do ódio e do conhecimento. Sobre o porquê da escolha de Bion como principal enfoque teórico, Zimerman (2010) explica:

Durante muitas décadas, todos os psicanalistas basearam os seus esquemas referenciais virtualmente em torno de dois vínculos, o do Amor (principalmente com base nos ensinamentos de Freud), e o do Ódio (fortemente apoiado nas concepções kleinianas), sendo que coube a Bion, sabidamente um analista com profundas raízes na escola de $M$. Klein e com um sólido embasamento freudiano, propor uma terceira natureza de vínculo: o do Conhecimento, o qual está diretamente ligado à aceitação, ou não, das verdades penosas, tanto as externas como também as internas, e que dizem respeito mais diretamente aos problemas da autoestima dos indivíduos. (p. 29)

Aos vínculos do amor, do ódio e do conhecimento formatados por Bion, Zimerman (2010) acrescenta o do reconhecimento, cuja principal acepção "alude à ânsia que todo o ser humano possui de ser reconhecido pelos demais, como sendo uma pessoa querida, aceita, desejada e admirada pelos seus pares e circunstantes" (p. 31).

Considerando esses sentimentos sempre presentes na vida de todo e qualquer ser humano, escolheu-se utilizar, como principal referencial da pesquisa realizada, as teorias do reconhecimento de Axel Honneth e a dos quatro vínculos de David Zimerman, para alicerçar a investigação e análise dos dados obtidos.

A investigação das formas de reconhecimento e a formação dos vínculos presentes na vida desses jovens, que se ampliam em programas como o Protejo, é fundamental para a boa execução de projetos que visam dar-lhes apoio. Isso porque promover a inserção social desses jovens não é tarefa fácil, somente possível mediante um trabalho que busque despertar neles um sentimento de pertencimento e bem-estar nos programas em que são atendidos.

\section{Projeção de vínculos e esferas de reconhecimento}

O Protejo atende jovens em situação de risco social, e, para a compreensão desse termo, é preciso que percebamos quem são os meninos e meninas atendidos pelos programas de políticas públicas de enfrentamento e prevenção da criminalidade juvenil e que estão em situação de risco social. Como quaisquer outros adolescentes, esses jovens encontram-se 
em uma peculiar condição de ser humano em intenso processo de desenvolvimento, e a partir dessa condição desencadeiam-se inúmeros fatores.

Para buscar a identidade desses jovens e revelar os sentimentos, vínculos e relações desenvolvidos por eles no decorrer da execução de programas como o Protejo, torna-se necessário ter em mente a realidade em que vivem, a convivência com suas famílias, seus anseios, suas histórias de vida e outros fatores essenciais a tal compreensão.

Conforme afirma Centurião (1999, p. 72), o profissional que se dedica a trabalhar com crianças e adolescentes deve possuir uma perspicácia psicológica capaz de lhe fornecer o suporte necessário para compreender a realidade desses meninos e meninas.

A pesquisa demonstrou que a permanência e a redução da evasão em programas como o Protejo está diretamente relacionada ao vínculo e ao reconhecimento que os jovens estabelecem com os profissionais.

A partir dos relatos dos jovens em suas entrevistas, resta que eles se sentem dentro do projeto como sujeitos possuidores de direitos e deveres, tanto seus quanto dos demais colegas, e até mesmo dos profissionais. É comum ouvir deles menções aos direitos que estão aprendendo a ter. Uma jovem relata que, antes do projeto, não sabia que era possível expressar a sua opinião. Dessa verificação apreende-se um reconhecimento jurídico, no sentido empregado por Honneth (2003), por parte dos jovens atendidos pelo projeto, e que está diretamente ligado com o sentimento de autorrespeito. Afinal,

um sujeito é capaz de se considerar, na experiência do reconhecimento jurídico, como uma pessoa que partilha com todos os outros membros de sua coletividade as propriedades que capacitam para a participação numa formação discursiva da vontade; e a possibilidade de se referir positivamente a si mesmo esse modo é o que podemos chamar de "auto-respeito". (Honneth, 2003, p. 200)

Por causa da complexidade e dos diversos aspectos subjetivos, nenhuma ciência isolada é capaz de lidar com todos os aspectos dos fatores de risco e de vulnerabilidade que envolvem a juventude. $\mathrm{O}$ estudo qualificado do comportamento dos jovens em situação de risco social só pode ser feito se integrados a conhecimentos advindos das diversas ciências. Além disso, por serem pessoas diferentes entre si e guardarem histórias próprias, cada uma com suas peculiaridades, torna-se impossível que esse estudo seja feito de forma única para todos. As vivências pessoais e a forma como cada ser humano lida com elas conferem-lhes uma individualização não apenas física ou biológica, mas também sociológica.
As histórias relatadas pelos jovens nas entrevistas revelaram a presença de vínculos e esferas de reconhecimentos em suas vidas, e, por isso, mais do que nunca o princípio da interdisciplinaridade precisa estar presente, pois esse necessita estar inserido no contexto dos estudos e pesquisas ligados às ciências humanas e sociais. No caso do atendimento aos adolescentes em situação de risco ou vulnerabilidade social, a presença e a compreensão de conteúdos sociológicos, biológicos, psicológicos, econômicos e familiares que giram em torno da vida desses jovens são de suma importância.

Essa variedade de vivências também é vislumbrada no que tange à formação das famílias dos jovens entrevistados. Os relatos revelaram estruturas familiares distintas, o que corrobora com os estudos de Zimerman (2010, p. 85), quando afirma que "da mesma forma como se passa com qualquer indivíduo, também o grupo familiar adquire uma determinada caracterologia típica, a qual varia bastante de um familiar para outro".

A principal esfera de reconhecimento e vínculo observados nas relações familiares é o "amor", que aqui deve ser entendimento em sua dimensão mais ampla. Portanto, a pesquisa empírica realizada para minha dissertação não envolveu simplesmente o levantamento das relações íntimas sexuais desses jovens, mas também das relações familiares, de amizade, e outras, em distintas dimensões.

Segundo Honneth (2003, p. 159), para se falar em "amor" deve-se empregar um conceito neutro do termo, e as relações amorosas devem ser compreendidas "como todas as relações primárias, na medida em que elas consistam em ligações emotivas fortes entre poucas pessoas, segundo o padrão de relações eróticas entre dois parceiros, de amizade e de relações pais/filhos". Baseando-se em Hegel, Honneth afirma que o amor representa a primeira esfera de reconhecimento recíproco, uma vez que nela os sujeitos confirmam mutuamente suas carências.

O desenvolvimento da esfera do amor nas famílias é de suma importância, uma vez que os sentimentos e as necessidades se traduzem como princípios de reconhecimento, necessários ao desenvolvimento de crianças e adolescentes. Uma família que supre as necessidades de suas crianças possibilita-lhes, em maior medida, o desenvolvimento de sua autoconfiança.

Nem todas as crianças e adolescentes, porém, residem em lares harmônicos e felizes, e a realidade demonstra cada vez mais a escassez (ou inexistência) de lares ditos "perfeitos". Afinal, a perfeição está em poder ser imperfeito e mesmo assim encontrar apoio e bem-estar no seio da família, realidade cada dia mais rara nos dias de hoje. De qualquer modo, a maneira como a criança e o adolescente se sentem (ou não) 
acolhidos dentro de casa reflete em seus comportamentos externos e em suas relações sociais.

Que a manutenção biológica, emocional e social da criança e do adolescente traz importante contribuição para o desenvolvimento de sua personalidade e caráter não há maiores discordâncias. A questão fundamental, e também a mais complexa, é saber a partir de que ponto perturbações em tais funções podem levar crianças e adolescentes a ingressar no âmbito da criminalidade juvenil e da violência. Bordin e Offord (2000) relatam que existem comportamentos que podem ser observados no curso do desenvolvimento normal de crianças e adolescentes, por exemplo, mentir e "matar" aula. Segundo os autores, para diferenciar normalidade de psicopatologia, é importante verificar se esses comportamentos ocorrem esporadicamente e de modo isolado, ou se constituem síndromes, representando um desvio do padrão esperado para pessoas da mesma idade e sexo em determinada cultura.

Ainda quanto às peculiaridades dos indivíduos e os vários aspectos que envolvem os fatores de ensejo à criminalidade, Abreu (1995, p. 6) afirma que

o argumento, mutatis mutandis, também serve às teorias psicogênicas, porque pessoas vivendo nas mesmas circunstâncias sociais, nem todas são criminosas. Não se impregnam e identificam da mesma forma. Sem nenhuma hesitação, mais uma vez acentue-se que são múltiplos os fatores conducentes ao crime.

Evidências disso encontram-se na pesquisa empírica que realizei, que identificou que, apesar de conviverem diariamente com casos de violência e com muitos aspectos de vulnerabilidade social, os jovens entrevistados não migraram para a criminalidade. Do mesmo modo, muitas famílias que convivem com conflitos diários acabam por encontrar saídas para lidar com as situações de adversidade e enfrentar seus problemas, pois, conforme aponta Zimerman (2010), o que vai definir se os desentendimentos fogem dos padrões normais é o tamanho e a intensidade dos conflitos.

Sabe-se que a adolescência e a juventude são fases complicadas no desenvolvimento do ser humano, pois é quando o jovem descobre um universo de opções quanto a seus caminhos possíveis para o futuro, e, ao mesmo tempo, vê-se diante da difícil tarefa de escolher entre todas essas possibilidades. Por isso, a base familiar torna-se tão importante para esse indivíduo que está a descobrir o mundo, afinal, "o bom relacionamento dos pais com seus filhos pode ser considerado fator de proteção para o cumprimento das tarefas de desenvolvimento dos adolescentes" (Sapienza; Pedromônico, 2005, p. 212).
Apesar de a criminalidade juvenil estar inserida no imaginário social como um atributo específico das camadas mais pobres, sabe-se que ela não é uma derivação restritiva da pobreza. A compreensão da violência ou da delinquência deve ser obtida a partir da análise dos diversos fatores que envolvem a questão. No caso dos adolescentes em situação de vulnerabilidade e risco social, a discussão envolve estigmas antigos, mas não superados pela sociedade. A imensa diferença social no Brasil contribui para que as classes mais pobres se tornem alvo da rotulação de comportamentos violentos e delinquenciais.

A situação de risco é própria da criança e do adolescente que convive com uma realidade de adversidades, seja por problemas econômicos, sociais, familiares, seja por questões psicológicas, como é o caso de muitos jovens entrevistados. E nesse quadro de risco, ao qual diversos jovens estão submetidos, o que mais chama a atenção é a negligência, tanto de pais e tutores dessas crianças e adolescentes quanto do Estado e também da sociedade como um todo. Muitos meninos e meninas veem suprimidos diariamente seus direitos fundamentais, tais como o direito à saúde, à alimentação, à educação, à cultura, ao lazer, à liberdade, à dignidade e ao respeito. Além da falta de tais direitos, esses jovens muitas vezes sofrem por carência e abandono daqueles que deveriam zelar pelo seu bem-estar. Fatores como gravidez precoce e indesejada, fome, alcoolismo, violência física e psicológica, exploração e abuso sexual, trabalho pesado, dependência e tráfico de drogas são apenas alguns dos problemas que se encontram constantemente presentes na vida de muitos adolescentes em situação de risco.

Além de todas essas formas de violência contra crianças e adolescentes, advindas pela ação de adultos ou de seus pares (irmãos, amigos, colegas etc.), a omissão também deve ser encarada como uma forma de violência, quando compromete o dever de proteger do adulto.

Todo o ato de omissão praticado contra crianças/adolescentes que implique uma transgressão do poder/ dever de proteção pelo adulto ou uma coisificação da infância, isto é, uma negação do direito que crianças e adolescentes têm de ser tratados como sujeitos e pessoas em condição peculiar de desenvolvimento, deve ser responsavelmente analisado pelas instâncias adequadas. (Trindade; Silva, 2004/2005, p. 246)

Corroborando com tal afirmativa, os relatos dos jovens entrevistados apontam uma série de negligência de seus pais e cuidadores, como violência doméstica e intrafamiliar, carência afetiva e ausência de educação sexual, de afeto e de proteção. 
Ainda no contexto da violência intrafamiliar, é interessante salientar também a violência chamada de institucional, resultante da precariedade de acesso aos serviços necessários de quem foi vítima dela. Ela inclui a falta de qualidade ou inadequação do atendimento e constitui mais um abuso a quem busca apoio após sofrer violência.

Violência intrafamiliar e institucional são formas agressivas e cruéis de se relacionar no interior das famílias, na escola e em instituições como albergues e internatos, produzindo danos físicos, emocionais, sexuais e, por vezes, até a morte. A violência intrafamiliar e a violência institucional são produzidas frequentemente tendo como justificativa educar e corrigir erros de comportamento de crianças e adolescentes. As violências social, intrafamiliar e institucional se expressam sob diferenciadas formas e, quando relacionadas às crianças e adolescentes, costumam ser classificadas como negligência, abuso físico, abuso sexual e abuso psicológico. (Souza; Jorge, 2006, p. 24)

Relatos dos jovens que recorreram a profissionais do Protejo para relatar problemas pessoais, inclusive casos de violência intrafamiliar, incluíam a busca de outros projetos da rede de assistência, mas nos quais foram maltratados. Os jovens relataram que, ao procurar os profissionais do Protejo sobre seus problemas, o acolhimento que receberam foi fundamental para que conseguissem falar sobre as questões mais penosas.

Salienta-se novamente que os fatores de risco não são encontrados de forma única e exclusiva nas classes desfavorecidas, pois, conforme já dito, famílias das classes média e alta também têm presentes tais fatores dentro de suas casas. O que muda é a visibilidade social e o melhor acesso aos meios de compreensão de revolta, presentes em qualquer adolescente, os quais nem sempre são acessíveis aos grupos mais vulneráveis. Neste sentido, é interessante a reflexão de Abramovay (2002), ao afirmar que

outro aspecto perverso da vulnerabilidade é a escassa disponibilidade de recursos materiais ou simbólicos a indivíduos ou grupos excluídos da sociedade. O não acesso a determinados insumos (educação, trabalho, saúde, lazer e cultura) diminui as chances de aquisição e aperfeiçoamento desses recursos que são fundamentais para que os jovens aproveitem as oportunidades oferecidas pelo Estado, mercado e sociedade para ascender socialmente. (p. 33)

Porém, cabe salientar que a vulnerabilidade, ou a própria exclusão social por si só, não impede a criança e o adolescente de seguir normas ou condutas. Exemplo disso encontra-se no comportamento de meninos e meninas de rua que desenvolvem uma expressividade própria, de um lado, sentindo-se iguais aos que compartilham as suas vivências, e de outro, sentindo-se diferentes daqueles que vivem em realidades opostas àquelas em que vivem. A partir disso, o menino de rua vai construindo a sua autoimagem, baseada no relacionamento que tem com os demais. $\mathrm{E}$, apesar de tais meninos não terem comportamentos considerados aceitáveis pelo restante da sociedade, isso não quer dizer que eles não tenham um código de conduta. Aliás, o sentimento de estar à margem, de fazer parte de um grupo diferenciado, de sentir-se de um modo diferente dos demais que compõem a sociedade, sendo encarados como "desviantes", faz com que esses meninos desenvolvam códigos restritos e específicos a seu grupo, que opera como grupo de "oposição" à sociedade abrangente (Centurião, 1999, p. 68).

Tal sentimento é similar àquele que envolve os jovens em situação de risco social, abrangendo inclusive o público-alvo atendido pelo Protejo. Muitos dos jovens são motivados, dentro e fora do projeto, pela procura de bem-estar e compreensão, e se identificam com aqueles que possuem uma realidade próxima à deles, ou que parecem entendê-los, distanciando-se daqueles com os quais não possuem tanta familiaridade, questão que também interfere na sua permanência ou não dentro do projeto.

$\mathrm{Na}$ investigação da dimensão coletiva, observou-se que os mesmos jovens que afirmam ter muitos amigos fora do projeto, sair nos fins de semana e participar de outras atividades externas, são aqueles que, dentro do projeto, possuem maior número de amigos.

O relacionamento dos jovens em grupo remete-nos ao vínculo que Zimerman (2010, p. 218) chama de reconhecimento, em que é de fundamental importância o convívio dos sujeitos em grupo. Neste sentido o autor afirma:

É essencial em toda e qualquer pessoa que ele viva e conviva em grupos, nas mais diferentes modalidades, desde o primeiro grupo de sua vida que é a inserção do recém-nascido em seu meio familiar (onde ele não será unicamente passivo, mas também muito ativo no processo de transformações que a família sofrerá a partir de sua inclusão). Depois, num ritmo progressivo, conviverá em grupos escolares, recreativos, sociais, esportivos, universitários, profissionais, artísticos e, naturalmente, os grupos terapêuticos etc., ocupando certos lugares, desempenhando determinados papéis e sempre influenciados pelos modelos, censuras e expectativas provindas dos primitivos pais e educadores em geral. (Zimerman, 2010, p. 218)

Centurião (2002) explica que essa forma de se relacionar é fortalecida pelo anonimato das grandes 
cidades, onde o indivíduo tem capacidade de perpetuar-se, ou então de viver com um senso de identidade, enquanto mantém os vínculos que o atam a um ou mais grupos primários de referência. Isso é importante, pontua o autor, para que esse indivíduo "possa viver relações 'face a face' e construir seus modelos de identificação" (p. 115), o que pode ser uma condição necessária para evitar a anomia pessoal.

A relação dos jovens com a escola revela-se um tanto problemática, considerando o relato comum de alguns deles sobre a evasão escolar. Muitos relatam que se matriculavam na escola, frequentavam alguns meses de aula e em seguida paravam de ir. Entre os motivos para o abandono citaram a necessidade e o desejo de trabalhar e a distância e dificuldade de deslocamento até a escola.

Outra questão responsável pelo abandono da escola e pela dificuldade de frequentá-la diz respeito ao termo que Fonseca (1993, p. 115) classifica como "circulação de crianças", ou seja, quando elas passam algum período fora de suas casas, morando com parentes, amigos, vizinhos etc. Isso foi relatado por alguns dos jovens entrevistados.

Os jovens veem a escola sob um prisma muito particular. Alguns reproduzem o discurso que ouvem nos projetos que participam, dizendo que é um bom lugar para que tenham um futuro melhor, enquanto outros explicam que há várias questões que os fazem parar de estudar: por não se sentirem acolhidos e reconhecidos, ou então por se sentirem reprimidos no ambiente escolar.

De um modo geral, revelam uma série de sonhos e objetivos traçados, e, ao mesmo tempo, certa insegurança quando à sua realização. Observa-se que grande parte dos jovens faz referência a quão importante seria para eles trabalhar sob o regime formal de trabalho, e sabem que esse é um objetivo possível. Mas revelam também outros desejos, como trabalhar em algo com o qual realmente se identifiquem, demonstrando certa insegurança quanto à viabilidade da realização de tal desejo.

Quanto ao Protejo, os jovens sentem-se valorizados pelo projeto, em razão de sua relação com os educadores e demais profissionais da equipe técnica. $O$ fato de as regras não terem sido passadas aos jovens de forma impositiva faz com que eles se sintam protagonistas no projeto, e por isso contribuem para a construção de suas atividades, o que lhes proporciona a noção de colaboração com o grupo, incidindo na esfera de reconhecimento que Honneth classifica como "solidariedade", ou seja, que se desenvolve mediante contribuições formais, fortalecendo a autoestima dos indivíduos. O autor explica que a autorrelação prática à qual uma experiência de reconhecimento faz os indivíduos chegarem é um "sentimento de orgulho como membro de um grupo social que está em condição de realizações comuns, cujo valor para a sociedade é reconhecido por todos os seus demais membros" (Honneth, 2003, p. 209), sentimento que é visível na fala dos jovens sobre suas realizações no projeto.

No discurso dos jovens nota-se também uma crença profunda no projeto, e, apesar de a duração deste ser de um ano, muitos deles, na época das entrevistas, ainda não aceitavam seu término. Se, por um lado, tal apego é essencial para garantir a permanência no projeto e reduzir a evasão, por outro, cria certa dependência dos jovens.

Essa negativação por parte dos jovens de que o projeto realmente iria terminar após o período de um ano tem a ver com o vínculo do conhecimento, no que diz respeito à dificuldade dos sujeitos de admitir verdades e circunstâncias desagradáveis ou penosas. A verdade, ou o seu oposto, como as falsificações, mentiras, distorções etc., exerce uma influência capital em toda e qualquer espécie de vínculo (Zimerman, 2010). Mas não é apenas quanto a esse aspecto da manutenção ou não do projeto que essa dificuldade de admitir circunstâncias penosas aparece na fala dos jovens. Em vários outros aspectos isso fica evidenciado, seja nos relacionamentos com seus parceiros amorosos, seja com amigos, ou questões relacionadas a trabalho, estudo, violência etc.

Observa-se que, com o Protejo, os jovens sentem-se seguros, tanto física quanto emocionalmente. Em suas falas, percebe-se o desenvolvimento tanto de vínculos quanto de esferas de reconhecimento no projeto, com os colegas e principalmente com os educadores e demais profissionais. Muitos jovens afirmaram que a presença dos educadores e a possibilidade de conversar e se "abrir" com eles são os principais motivos que os fazem sair de casa para ir até o local onde o projeto é desenvolvido.

Ao mesmo tempo, justamente por terem encontrado um apoio muitas vezes ausente em suas vidas, os jovens sofrem com certa dependência e expectativa em relação ao trabalho dos educadores, como se estes fossem permanecer ao lado deles por um longo período de tempo, ou seja, eles não têm muito claro o que fazer após o término do projeto.

\section{Considerações finais}

A juventude é acompanhada por uma série de transformações físicas e psíquicas que afetam o seu desenvolvimento. Transformações sociais também marcam a vida desses indivíduos, tanto na socialização primária quanto secundária.

A projeção de esferas de reconhecimento e a articulação de vínculos são essenciais na vida dos seres 
humanos. Por possuir a peculiaridade de encontrar-se em uma fase de intenso processo de desenvolvimento, a projeção e a articulação mencionadas ocorrem com muito mais intensidade na fase juvenil.

Grande parte dos programas de atendimento a jovens em situação de risco social volta a sua atenção aos fatores objetivos que influenciam o ingresso do jovem na criminalidade juvenil, tais como dificuldades econômicas, tráfico e uso de drogas, prevenção à criminalidade e à violência. Porém, a atenção a fatores subjetivos, que dizem respeito ao relacionamento que os jovens estabelecem, dentro e fora de um projeto, com seus colegas e com os profissionais das equipes técnicas, muitas vezes é deixada em segundo plano. No entanto, a investigação desses fatores subjetivos é de fundamental importância para a aceitação dos projetos pelos jovens e o consequente êxito daqueles em atendê-los.

O Projeto de Proteção a Jovens em Território Vulnerável (Protejo) é um interessante por articular ações pedagógicas e de prevenção à criminalidade juvenil. O Protejo faz parte das ações do Programa Nacional de Segurança Pública com Cidadania (Pronasci), que se revela como uma tentativa de inovar no controle social. Porém, o Pronasci apresenta diversos entraves na implantação e execução de seus projetos. Exemplo disso encontra-se no fato de que estes são executados em parceria com prefeituras, e grande parte dos coordenadores das ações implantadas nos territórios de paz possui vinculação político-partidá- ria, o que engessa o desenvolvimento e a continuidade de muitas delas.

O Protejo, implantado no território de paz do bairro Santo Afonso em Novo Hamburgo (RS), mostrou-se positivo na vida dos jovens, no sentido de que os entrevistados revelaram em seus relatos reflexos de vínculos e esferas de reconhecimento em suas vidas dentro e fora do projeto.

Os jovens veem o Protejo como uma forma de se "ocupar", sair de casa e se divertir com os amigos. Apesar de um ou outro incidente, os profissionais do projeto conseguiram evitar, na medida do possível, a ocorrência de conflitos de maiores proporções, no que diz respeito à violência.

O grande problema encontra-se no fato de muitos jovens verem-se como dependentes do projeto e da rede de assistência do bairro, e não acreditarem que o Protejo fosse mesmo se encerrar ao término do período de um ano, o que se traduziu em uma série de frustrações para eles.

Apesar de seus entraves, ações como o Protejo possuem um grande potencial transformador na vida dos jovens participantes. No entanto, há ainda muito a ser aprimorado, no que tange às políticas públicas brasileiras, para que estas passem a ser políticas de governo, e não meramente políticas partidárias, ou seja, que estejam voltadas para uma atenção especial ao trabalho de emancipação dos indivíduos que delas são destinatários.

\section{Referências}

ABRAMOVAY, Miriam et al. Juventude, violência $e$ vulnerabilidade social na América Latina: desafios para políticas públicas. Brasília: Unesco/BID, 2002.

ABREU, Waldir de. A corrupção penal infantojuvenil. Rio de Janeiro: Forense, 1995.

BRASIL. Ministério da Justiça. Programa Nacional de Segurança Pública com Cidadania. Manual de Convênios, Brasília, 2008.

BORDIN, Isabel A. S.; OFFORD, David R. Transtorno de conduta e comportamento anti-social. Revista Brasileira de Psiquiatria, v. 22, s. 2, São Paulo, dez. 2000. Disponível em: <http://www.scielo.br/scielo.php?script=sci_arttext \&pid=S1516-44462000000600004>. Acesso em: 20 ago. 2008.

CENTURIÃO, Luiz Ricardo Michaelsen. Alguns aspectos do menor de rua e seu contexto. In: GAUER, Gabriel José Chittó; GAUER, Ruth Maria Chittó (Orgs.). A fenomenologia da violência. Curitiba: Juruá, 1999. p. 65-91.

FONSECA, Cláudia. Criança, família e desigualdade social no Brasil. In: RIZZINI, Irene. A criança no Brasil hoje: desafios para o terceiro milênio. Rio de Janeiro: Universitária Santa Úrsula, 1993. p. 113-132.

HONNETH, Axel. Luta por reconhecimento: a gramática moral dos conflitos sociais. São Paulo: Editora 34, 2003.

SAPIENZA, Graziela; PEDROMÔNICO, Márcia Regina Marcondes. Risco, proteção e resiliência no desenvolvimento da criança e do adolescente. Psicologia em Estudo, Maringá, SP, v. 10, n. 2, p. 209-216, 2005.

SOUZA, Edinilsa Ramos de; JOR GE, Maria Helena Prado de Mello. Impacto da violência na infância e adolescência brasileiras: magnitude da morbimortabilidade. In: LIMA, Cláudia Araújo de et al. Violência faz mal à saúde. Brasília: Ministério da Saúde, 2006. p. 23-28.

TRINDADE, Jorge; SILVA, Milena Leite. Crianças e adolescentes vítimas de violência: envolvimento legal e fatores psicológicos estressores. Revista do Ministério Público do Rio Grande do Sul, Porto Alegre, n. 54, p. 243-264, out./2004 - abr./2005.

ZIMERMAN, David. Os quatro vínculos: amor, ódio, conhecimento reconhecimento na psicanálise e em nossas vidas. Porto Alegre: Artmed, 2010. 


\title{
Un análisis del Proyecto de Área de Protección a los Jóvenes Vulnerables a partir de vínculos y reconocimiento
}

\section{Resumen}

En este artículo se analiza la proyección de los vínculos y las esferas de reconocimiento en la vida de los jóvenes que participan en el Proyecto de Protección a Jóvenes en Territorio Vulnerable - PROTEJO en Brasil. Este análisis se realiza a partir de las teorías desarrolladas por David Zimerman y Axel Honneth. Se empleó un procedimiento metodológico para llevar a cabo entrevistas semiestructuradas. En conclusión, se encontró que la formación de enlaces y esferas de reconocimiento en la vida de los jóvenes en toda su socialización influye directamente en sus vidas y sus relaciones adentro y fuera del proyecto. A pesar de mostrar algunas fallas en el sentido de no preparar a los jóvenes para la realización y la suspensión del proyecto, el PROTEJO se muestra como positivo en las vidas de los jóvenes mediante el fortalecimiento de los vínculos y la formación de esferas de reconocimiento investigados.

Palabras clave: juventud, sociedad, políticas públicas, reconocimiento, vínculos.

\section{An analysis from the point of view of links and recognitionof theProtection of Teenagers in Vulnerable Territory Project}

\begin{abstract}
The article analyzes the projection of cultural linkage and spheres of recognition in the lives of teenagers participating in the Protection of Teenagers in Vulnerable Territory Project (PROTEJO) in Brazil. Analyzed based on theories developed by David Zimerman and Axel Honneth, methodological procedure was employed to carry out semi-structured interviews. In conclusion, the findings verify that the formation of bonds and spheres of recognition in the lives of young people throughout their socialization directly influence their daily lives and relationships within and outside the project. Despite some flaws in the preparation for the final portion the program, the project proved to be a positive force in the lives of teenagers by strengthening the formation of links and spheres of recognition in areas researched.
\end{abstract}

Key words: youth, society, public policy, recognition, ties.

Data de recebimento do artigo: 18/10/2013

Data de aprovação do artigo: 28/1/2014 